\title{
Effect of low dose X-ray on membrane fluidity of thalassemic red blood cells
}

\author{
C. Udomtanakunchai ${ }^{1}$, S. Mernsri $^{2}$, S. Jeejai ${ }^{2}$, N. Intachai ${ }^{1}$, \\ C. Ruengdit $^{2}$, S. Pornprasert ${ }^{2}$ \\ ${ }^{1}$ Department of Radiologic Technology, Faculty of Associated Medical Sciences, Chiang Mai University, Chiang Mai,
Thailand \\ ${ }^{2}$ Department of Medical Technology, Faculty of Associated Medical Sciences, Chiang Mai University, Chiang Mai, \\ Thailand
}

\section{- Original article}

*Corresponding authors:
Sakorn Pornprasert, PhD.,
E-mail:
$\quad$ sakornmi001@gmail.com
Revised: January 2020
Accepted: February 2020
Int. J. Radiat. Res., January 2021;
19(1): 75-80
DOI: 10.29252/ijrr.19.1.55

\begin{abstract}
Background: Chest X-ray is one of the examinations required for an annual health checkup. The interaction of radiation to the medium produces free radicals, which consequently causes biological changes either structural or properties of the cells. Whether the radiation from Chest X-ray upright technique affects the plasma membrane fluidity of thalassemic red blood cells (RBCs) is still unclear. Materials and Methods: Whole blood samples of nonthalassemia group (G1), non-clinically significant thalassemia group (G2) and clinically significant thalassemia group (G3) were irradiated with the Chest $X$ ray upright technique with a dose of $6.57 \mu \mathrm{Sv}(90 \mathrm{kVp})$. One-tube osmotic fragility (OF) test, dichlorophenol-indophenol (DCIP) test for hemoglobin $E$ ( $\mathrm{HbE})$ screening and glucose-6-phosphate dehydrogenase (G6PD) activity analysis were performed on those samples. Results: The \% OF values of G1 and $\mathrm{G} 3$, between irradiated and non-irradiated RBCs, were comparable, while those of G2 were significantly increased. However, the irradiation did not affect $\mathrm{HbE}$ screening test by DCIP technique in G2. In addition, it did not alter the G6PD activity in both thalassemia and non-thalassemia samples. Conclusion: Chest X-ray upright technique with a dose of $6.57 \mu \mathrm{Sv}(90 \mathrm{kVp})$ did not alter the membrane fluidity and the G6PD activity of thalassemic and non-thalassemic RBCs. Thus, it did not affect the thalassemia screening by OF and DCIP tests. However, increasing \% OF value in $\mathrm{HbE}$ trait might be used as one of the screening test for $\mathrm{HbE}$ trait.
\end{abstract}

Keywords: X-ray, radiation, thalassemia, osmotic fragility, red blood cell

\section{INTRODUCTION}

Thalassemia and hemoglobinopathy are inherited hemoglobin $(\mathrm{Hb})$ disorders that result in a production of structurally abnormal $\mathrm{Hb}$ variants or a reduction in the synthesis of structurally normal $\mathrm{Hb}$, consequently, to red cell pathology. These diseases are generally spread especially in Southeast Asia, Southern China, Africa, Middle East and Mediterranean. In Thailand, a-thalassemia, $\beta$-thalassemia and $\mathrm{HbE}$ ( $\beta 26$ (B8) Glu $\rightarrow$ Lys, GAG $>$ AAG) are prevalent. The incidences are $20-30 \%$ for $\alpha$-thalassemia, 3-
$9 \%$ for $\beta$-thalassemia and up to $54 \%$ for $\mathrm{HbE}$ (1). In order to provide a rapid method for identifying thalassemia in a region with massive population and limited resources, the preliminary screening of $\alpha$ - and $\beta$-thalassemia is performed using one-tube osmotic fragility (OF) test (2) and/or mean corpuscular volume (MCV) $(3,4)$ whereas the screening of $\mathrm{HbE}$ is performed using dichlorophenol-indophenol (DCIP) test (5).

The Chest X-ray upright is one of the annual health checkup methods to assess lung function. The lung function test is included in not only for healthy persons, but also in ongoing medical 
care of patients. Other than Chest X-ray, the dual -energy X-ray absorptiometry (DXA) is required for osteoporosis at eight years of age and annually thereafter, as necessary (6-8). The effective doses for Chest X-ray technique (7.00$50.00 \mu \mathrm{Sv})$ and DXA technique (9.00-27.00 $\mu \mathrm{Sv}$ ) can be classified as low dose level $(9,10)$. A previous study showing that the medical diagnostic X-ray at 50, 70, and $100 \mathrm{kV}$ did not influence hemolysis, osmotic fragility and fluorescence anisotropy values of irradiated red blood cells (RBCs) from normal individuals (11). However, there has been no report about the effect of diagnostic X-ray on thalassemic RBCs. The aim of this study was to analyze the effect of radiation used for Chest X-ray on the RBC fragility of thalassemia subjects.

\section{MATERIALS AND METHODS}

\section{Blood samples and thalassemia diagnosis}

Ethylenediaminetetraacetic acid (EDTA) blood samples were obtained from the Thalassemia Laboratory, Associated Medical Sciences-Clinical Service Center (AMS-CSC), Chiang Mai University, Chiang Mai, Thailand, where red cell parameters including, RBC counts, Hb, packed cell volume (PCV), MCV and mean corpuscular $\mathrm{Hb}(\mathrm{MCH})$ were analyzed by the ADVIA 2120i hematology analyzer (Siemens Healthcare Diagnostic, Deerfield, IL, USA) while quantification of $\mathrm{HbA}_{2}$ (for detection of $\beta$-thalassemia) and identification of hemoglobinopathies including $\mathrm{HbE}$ were performed by using capillary electrophoresis (Capillarys $^{\mathrm{TM}} 2$ Flex Piercing; Sebia, Norcross, GA, USA). In addition, the molecular diagnosis for $\alpha^{0}$-thalassemia (SEA and Thai type deletions) was detected by real-time PCR with SYBR Green1 and high resolution melting (HRM) analysis as previously described $(12,13)$. Ethical procedures for using the samples that are outside the primary purpose were reviewed and approved by the Ethics Committee of the Faculty of AMS, Chiang Mai University, Chiang Mai, Thailand (ethical approval number AMSEC-61EX -048).

\section{Radiation exposure}

The radiation output was quantified using an ion chamber detector (Radcal, 10X6-6, USA). On the same day of blood collection, $100 \mu \mathrm{L}$ EDTA whole blood samples of thalassemia and non-thalassemia subjects were aliquoted into $1.5 \mathrm{ml}$ micro-tubes and irradiated by using an X-ray machine (Shimadzu, Collimator type R-20J, Japan) utilizing Chest X-ray upright technique (90 kVp $100 \mathrm{~mA} 0.071$ second, Field size 14" $\times 17$ ", Source to Sample Distance 72").

\section{Determination of the RBC osmotic fragility}

The OF test was performed to determine the degree of RBC hemolysis immediately after the blood sample was irradiated. The $20 \mu \mathrm{L}$ of irradiated and non-irradiated RBCs were suspended into $5 \mathrm{~mL}$ of $0.36 \%$ buffered saline solution (BSS) and $5 \mathrm{~mL}$ of distilled water (DW). The solutions were then placed at room temperature for 5 minutes, and centrifuged at $3000 \mathrm{rpm}$, for 5 minutes. The optical density (OD) of released hemoglobin in saline solution and distilled water was determined by spectrophotometer at $540 \mathrm{~nm}(14,15)$. The percentages of the hemolysis ( $\%$ OF) were calculated as follow: $\%$ OF $=\left(\mathrm{OD}_{\mathrm{BSS}} / \mathrm{OD}_{\mathrm{DW}}\right) \times 100$ and those with cut-off values of less than $85 \%$ were used for the thalassemia screening (14). In addition, the delta-osmotic fragility $(\triangle \mathrm{OF})$ was also calculated as follow: $\Delta \mathrm{OF}=\mathrm{OF}_{\mathrm{X}}-\mathrm{OF}_{\mathrm{NX}}$. Where, the $\mathrm{OF}_{\mathrm{X}}$ and $\mathrm{OF}_{\mathrm{NX}}$ were percentages of the $\mathrm{OF}$ values of irradiated and non-irradiated RBCs, respectively.

\section{Assessment the effect of radiation on $\mathrm{HbE}$ screening and G6PD activity}

We hypothesized that radiation might produce reactive oxygen species (ROS) that affects the precipitation of unstable $\mathrm{Hb}$, especially $\mathrm{HbE}$. Furthermore, we hypothesized that the G6PD activity might be affected by ROS produced since G6PD is one part of a ROS elimination pathway. Thus, irradiated and non-irradiated RBCs from five non-thalassemia subjects and five $\mathrm{HbE}$ traits were randomly selected and tested with the DCIP kit (Thalcon ${ }^{\circledR}$-DCIP, Surathin International Co., Ltd., Samutprakarn, Thailand) according to 
manufacturers' instructions. The optical density (OD) of precipitated $\mathrm{HbA}$ and $\mathrm{HbE}$ in DCIP solution were measured by spectrophotometer at a wavelength range of $800 \mathrm{~nm}$ as described previously (16). In addition, the G6PD activity was also analyzed by using the CareStart ${ }^{\mathrm{TM}}$ G6PD Biosensor (AccessBio, NJ, USA) according to manufacturers' instructions.

\section{Statistical analysis}

Descriptive data were informed as of the mean \pm standard deviation (SD). The statistical analysis was performed by Origin Pro8 Software. All obtained parameters were analyzed within group (irradiated RBCs and non-irradiated RBCs) by using paired sample t-test and between groups by using One-way ANOVA (Tukey procedure). The $p<0.05$ was considered statistically significant.

\section{RESULTS}

The radiation output of this X-ray machine was determined for 10 times. The result indicating the dose rate of X-ray machine that used for Chest X-ray technique at the energy of $90 \mathrm{kVp} 0.071$ second was $1.32 \pm 0.02 \mathrm{mGy} / \mathrm{s}$. The effective dose for each sample was about $6.57 \mu \mathrm{Sv}$. Based on thalassemia diagnostic results, the 108 studied samples could be divided into three groups: G1) non-thalassemia group ( $\mathrm{n}=50), \mathrm{G} 2$ ) non-clinically significant thalassemia group ( $\mathrm{n}=27)$ and G3) clinically significant thalassemia group $(\mathrm{n}=31)$. The characteristics, thalassemia types and red cell parameters of each group are shown in table 1 . The lowest mean levels of $\mathrm{Hb}$, packed cell volume (PCV), MCV and mean corpuscular $\mathrm{Hb}$ $(\mathrm{MCH})$, and the highest mean level of RBCs were observed in G3. Mean \pm SD of the $\%$ OF value for non-irradiated RBCs of G1 was $93.84 \pm 4.84 \%$, which was higher than the cut-off value (85\%) for thalassemia screening while those of G2 and G3 were lower $(82.74 \pm 15.09 \%$ and $41.10 \pm$ $20.58 \%$, respectively). However, the $\%$ OF values between non-irradiated and irradiated RBCs of G1 and G3 were comparable while in G2, the $\%$ OF values of irradiated RBCs were significantly increased than those of the non-irradiated (figure 1). In addition, the $\Delta \mathrm{OF}$ mean of the G2 were significantly higher than those of the G1 but not of the G3 (figure 2).

The HbE trait samples had higher OD values of precipitated $\mathrm{HbA}$ and $\mathrm{HbE}$ in the DCIP solutions than those of the non-thalassemia samples. However, the OD values between irradiated and non-irradiated RBCs in each group of $\mathrm{HbE}$ trait samples and non-thalassemia samples were not significantly different (figure 3). Moreover, the values of G6PD activity between irradiated and non-irradiated RBCs in each subject group of non-thalassemia and thalassemia samples were also comparable (figure 4).

Table 1. The characteristics, thalassemia types and red cell parameters of each sample group.

\begin{tabular}{|c|c|c|c|c|c|c|c|c|}
\hline Subject Groups & $\alpha$ - and $\beta$-thalassemias & Age (Years) & $\begin{array}{c}\text { Male/ } \\
\text { Female }\end{array}$ & $\mathrm{Hb}(\mathrm{g} / \mathrm{dL})$ & PCV (L/L) & $\begin{array}{l}\text { RBCs (x } \\
\left.10^{12} / \mathrm{L}\right) \\
\end{array}$ & MCV (fL) & $\mathrm{MCH}(p g)$ \\
\hline $\begin{array}{c}\text { G1: Non- } \\
\text { thalassemia }(n=50)\end{array}$ & Normal individual $\left(\alpha \alpha / \alpha \alpha ; \beta^{A} / \beta^{A}\right)$ & \begin{tabular}{|c|}
$33.63 \pm 14.9$ \\
$5(16.0-$ \\
$78.0)$ \\
\end{tabular} & $20 / 30$ & \begin{tabular}{|c|}
$13.20 \pm 1.9$ \\
$1(8.3-$ \\
$17.0)$ \\
\end{tabular} & $\begin{array}{c}0.40 \pm 0.0 \\
5(0.27- \\
0.52)\end{array}$ & $\begin{array}{c}4.77 \pm 0 . \\
67 \\
(3.0-6.1)\end{array}$ & $\begin{array}{c}85.93 \pm 6 . \\
18(80- \\
112) \\
\end{array}$ & \begin{tabular}{|c|}
$27.69 \pm 1.3$ \\
$1(25.1-$ \\
$30.3)$ \\
\end{tabular} \\
\hline $\begin{array}{c}\text { G2: } \begin{array}{c}\text { Non-clinically } \\
\text { significant } \\
\text { thalassemia }(n=27)\end{array} \\
\text { themis }\end{array}$ & HbE trait $\left(\alpha \alpha / \alpha \alpha ; \beta^{E} / \beta^{A}\right)$ & $\begin{array}{c}17.38 \pm 6.44 \\
(3.0-25.0)\end{array}$ & $13 / 14$ & \begin{tabular}{|c|}
$12.14 \pm 1.8$ \\
$9(7.2-$ \\
$16.9)$ \\
\end{tabular} & $\begin{array}{c}0.36 \pm 0.0 \\
5(0.22- \\
0.47)\end{array}$ & $\begin{array}{c}4.84 \pm 0 \\
64 \\
(3.7-6.0)\end{array}$ & \begin{tabular}{|c|}
$74.64 \pm 7$ \\
$51(52-$ \\
$86)$ \\
\end{tabular} & \begin{tabular}{|c|}
$25.1 \pm 2.56$ \\
$(18.3-$ \\
$29.5)$ \\
\end{tabular} \\
\hline $\begin{array}{c}\text { G3: Clinically } \\
\text { significant } \\
\text { thalassemia }(n=31)\end{array}$ & $\begin{array}{c}\alpha \text {-thal trait }\left(--/ \alpha \alpha ; \beta^{\mathrm{A}} / \beta^{\mathrm{A}} ; n=6\right) \\
\text { HbH disease }\left(--/-\alpha ; \beta^{\mathrm{A}} / \beta^{\mathrm{A}} ; n=5\right) \\
\beta \text {-thal trait }\left(\alpha \alpha / \alpha \alpha ; \beta^{\top} / \beta^{\mathrm{A}} ; n=11\right) \\
\alpha \text { - and } \beta \text {-thal traits }\left(--/ \alpha \alpha ; \beta^{\mathrm{T}} / \beta^{\mathrm{A}} ; n=3\right) \\
\alpha \text {-thal and HbE traits }\left(--/ \alpha \alpha ; \beta^{\mathrm{E}} / \beta^{\mathrm{A}} ; n=1\right) \\
\text { Homozygous HbE }\left(\alpha \alpha / \alpha \alpha ; \beta^{\mathrm{E}} / \beta^{\mathrm{E}} ; n=3\right) \\
\alpha \text {-thal trait and homozygous HbE } \\
\left(--/ \alpha \alpha ; \beta^{\mathrm{E}} / \beta^{\mathrm{E}} ; \mathrm{n}=2\right)\end{array}$ & $\begin{array}{l}36.17 \pm 18.6 \\
9(1.0-68.0)\end{array}$ & $16 / 15$ & $\mid \begin{array}{c}10.38 \pm 2.4 \\
6(4.7- \\
15.7)\end{array}$ & $\begin{array}{c}0.33 \pm 0.0 \\
7(0.16- \\
0.48)\end{array}$ & $\left|\begin{array}{c}5.14 \pm 1 \\
24 \\
(2.1-7.7)\end{array}\right|$ & \begin{tabular}{|c|}
$64.90 \pm 9$. \\
$90(47-$ \\
$82)$
\end{tabular} & $\begin{array}{c}20.48 \pm 2.8 \\
3(15.5- \\
26.7)\end{array}$ \\
\hline
\end{tabular}




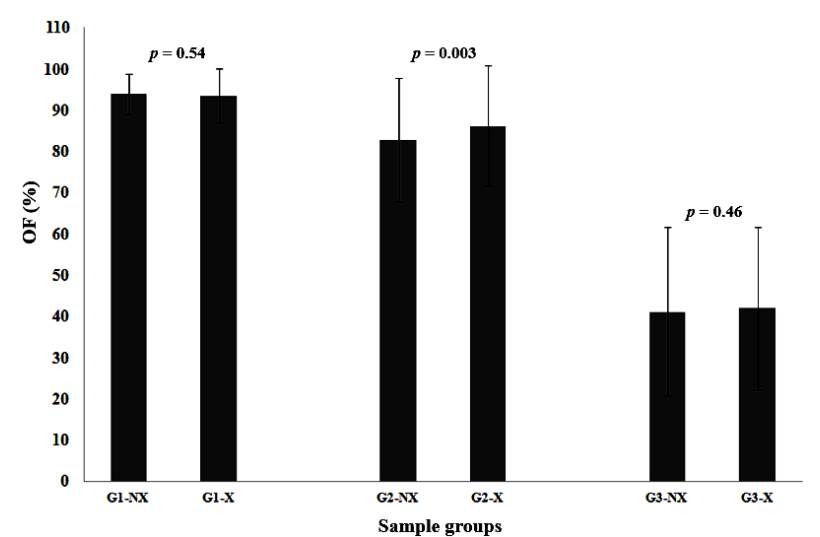

Figure 1. The osmotic fragility of non-irradiated and irradiated RBCs among the three groups of samples. Data are presented as mean and standard deviation (SD). G1, G2 and

G3 are non-thalassemia group $(n=50)$, non-clinically significant thalassemia group $(n=27)$ and clinically significant thalassemia group ( $n=31$ ), respectively while $X$ and NX are $\mathrm{X}$-ray and Non X-ray, respectively.

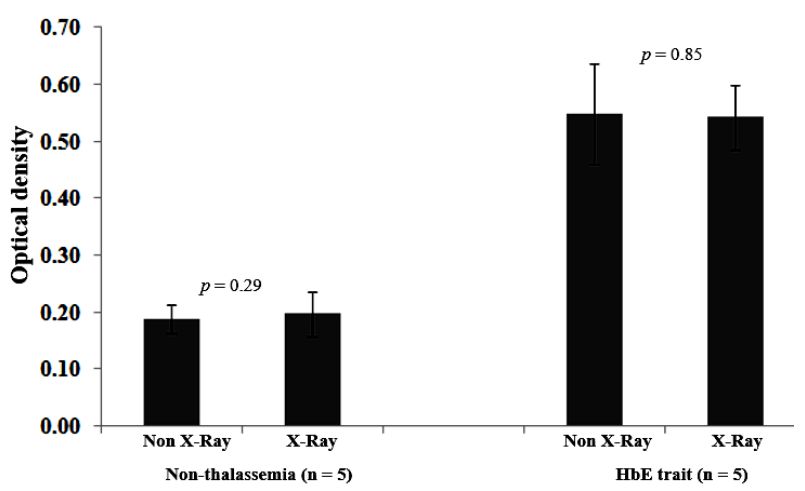

Figure 3. The optical density (OD) of precipitated $\mathrm{HbA}$ and $\mathrm{HbE}$ in DCIP solution between irradiated and non-irradiated RBCs among two groups of non-thalassemia and $\mathrm{HbE}$ trait subjects. Data are presented as mean and standard deviation (SD).

\section{DISCUSSION}

$\mathrm{X}$-ray is high-energy electromagnetic radiation causes matter ionization during the interaction. The matter ionization induces a free radical formation, in which produces a variety of changes in cell membrane. Normally, in a whole blood system, an anti-oxidant capacity decreases after the X-ray irradiation, in which it will lead to cause an abundance of

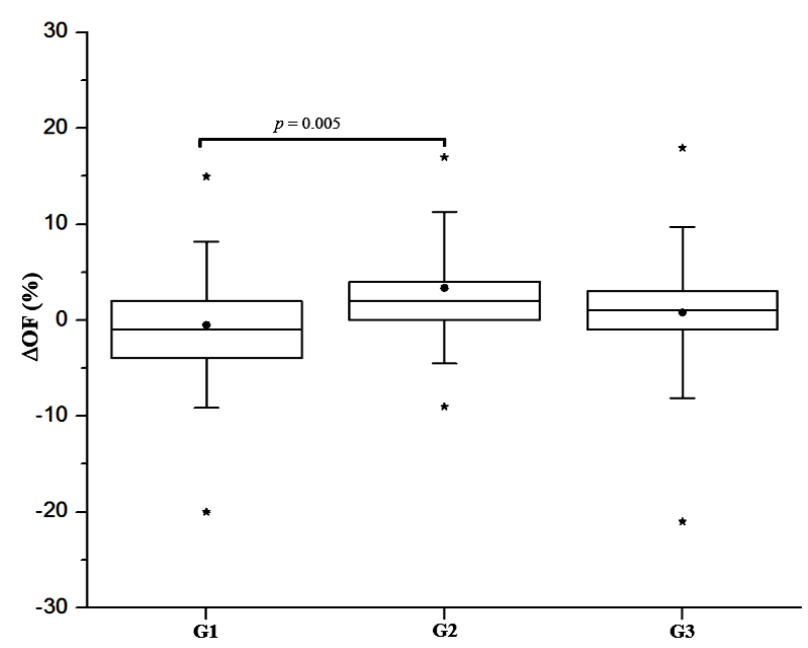

Figure 2. The delta-osmotic fragility ( $\triangle \mathrm{OF}$ ) of plasma membrane of red blood cells among the three groups of samples. Data are presented as median (horizontal line) and mean (black circle) while the box represents percentile 25 and

75 , the upper and lower whiskers represent standard deviation (SD), and the maximum and minimum values are shown as $\operatorname{star}(*)$. G1, G2 and G3 are non-thalassemia group $(n=50)$, non-clinically significant thalassemia group $(n=27)$ and clinically significant thalassemia group $(n=31)$, respectively.

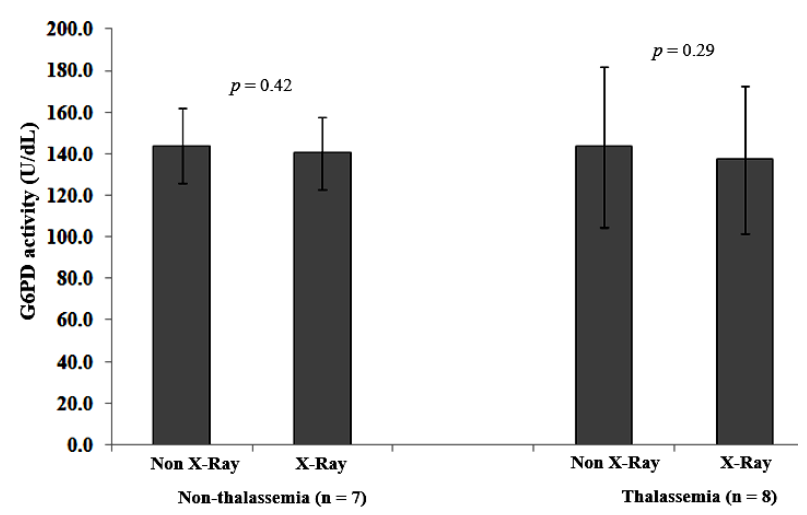

Figure 4. The G6PD activity between irradiated and non-irradiated RBCs among two groups of non-thalassemia and thalassemia subjects. Data are presented as mean and standard deviation (SD).

polyunsaturated lipids on red cell membranes and initiate lipid peroxidation by free radicals 117 , 18). In the current study, red blood cells of non-thalassemia and thalassemia subjects were directly exposed to the X-ray at the radiation dose of about $6.57 \mu \mathrm{Sv}(90 \mathrm{kVp})$. Red blood cells from non-thalassemia subjects showed similarity of diagnostic X-ray results at energy of 50 to 100 $\mathrm{kVp}$, which did not induce any changes in osmotic fragility after irradiation for $30 \mathrm{~min}$ (11).

Int. J. Radiat. Res., Vol. 19 No. 1, January 2021 
Moreover, in the clinically significant thalassemia group (G3), the osmotic fragility did not change after irradiation. These results exhibited that the red blood cell membrane fluidity of non-thalassemia and clinically significant thalassemia samples did not respond to low dose radiation. Even though the low dose irradiation did not show significant effect on cell membrane, the alteration of cell membrane however was observed in human peripheral blood mononucleated cells ${ }^{(19)}$. Surprisingly, the red blood cells from non-clinically significant thalassemia subjects responded on the irradiation by increasing their osmotic fragility. This indicates that the radiographic examination such as chest X-ray or DXA prior blood sample collection might change the red blood cell osmotic fragility in this subject group. All subjects in the group of non-clinically significant thalassemia were $\mathrm{HbE}$ trait, thus, the RBC irradiation procedure can be used as one of the screening tests for $\mathrm{HbE}$ trait. However, the appropriated cut-off values of increasing \% OF and $\triangle \mathrm{OF}$ are needed to be further studied in a larger population.

Generally, the screening of $\mathrm{HbE}$ is performed by using DCIP test whereas the OF test is not recommended for $\mathrm{HbE}$ screening $(20,21)$. Therefore, the irradiated and non-irradiated RBCs from non-thalassemia individuals and $\mathrm{HbE}$ traits were randomly selected and tested with the DCIP kit (Thalcon ${ }^{\circledR}$-DCIP, Surathin International Co., Ltd., Samutprakarn, Thailand). The study showed that the OD value of precipitated $\mathrm{HbA}$ and $\mathrm{HbE}$ in DCIP solution between irradiated and non-irradiated RBCs in each subject group were not significantly different (figure 3). In addition, the G6PD activity, which plays a role in protecting cells from potentially harmful molecules (the ROS) between irradiated and non-irradiated RBCs in each subject group of non-thalassemia and thalassemia subjects were also comparable (figure 4). These results correspond with the previous study by Smith et al who found that low dose ionizing radiation produces too little ROS to directly affect antioxidant concentration in cells (22). Therefore, taken together, the present study demonstrated that the Chest X-ray upright technique with a dose of $6.57 \mu \mathrm{Sv}$ (90 $\mathrm{kVp}$ ) did not alter the membrane fluidity of thalassemic RBCs and also did not affect the thalassemia screening test results. The increasing values of $\% \mathrm{OF}$ and $\triangle \mathrm{OF}$ in irradiated RBCs of HbE trait could be used as one of screening test for $\mathrm{HbE}$ trait.

\section{ACKNOWLEDGMENTS}

The authors thank technicians in the Associated Medical Sciences-Clinical Service Center (AMS-CSC), Faculty of Associated Medical Sciences, Chiang Mai University, Chiang Mai, Thailand for their help and assistance. We are also grateful to Kallayanee Treesuwan, AMS-CSC, Chiang Mai University, Chiang Mai, Thailand, for refinement of the English language.

This study was supported in part by grants from the Teaching Assistant and Research Assistant (TA/RA) scholarships, Graduate School, Chiang Mai University, Chiang Mai, Thailand.

\section{Conflicts of interest: Declared none.}

\section{REFERENCES}

1. Fucharoen $S$ and Winichagoon $P$ (2011) Haemoglobinopathies in southeast Asia. Indian J Med Res, 134(4): 498-506.

2. Sirichotiyakul S, Tantipalakorn C, Sanguansermsri $T$, Wanapirak C, Tongsong T (2004) Erythrocyte osmotic fragility test for screening of alpha-thalassemia-1 and beta -thalassemia trait in pregnancy. Int J Gynaecol Obstet, 86 (3): 347-350.

3. Nathalang $\mathrm{O}$, Nillakupt K, Arnutti P, Boonsiri T, Panichkul S, Areekul W (2005) Screening for thalassemia and hemoglobinopathy in a rural area of Thailand: a preliminary study. J Med Assoc Thai, 88(Suppl 3): 35-42.

4. Tatsumi N, Tsuda I, Funahara Y, Bunyaratvej A, Fucharoen $S$ (1992) Automatic measurement of hemoglobin $F$ in blood obtained from patients with hemoglobin $E / E$ and beta-thalassemia/hemoglobin/E. Southeast Asian J Trop Med Public Health, 23(Suppl 2): 91-94.

5. Kulapongs P, Sanguansermsri T, Merty G, Tawarat S (1976) Dichlorophenolindophenol (DCIP) precipitation test: a new screening test for $\mathrm{Hb}$ E and $\mathrm{H}$. Pediatr Soc Thailand, 15: 17. 


\section{Udomtanakunchai et al. / Low dose X-ray on thalassemic RBC membrane fluidity}

6. Fung KP, Chow OK, So SY, Yuen PM (1987) Pulmonary function in thalassemia major. J Pediatr, 111(4): 534-537.

7. Vichinsky E and Levine L (2012) Standards of Care Guidelines for Thalassemia. Children's Hospital \& Research Center, Oakland, CA.

8. Willen SM, Cohen R, Rodeghier M, Kirkham F, Redline SS, Rosen C, et al. (2018) Age is a predictor of a small decrease in lung function in children with sickle cell anemia. Am J Hematol, 93(3): 408-415.

9. Damilakis J, Adams JE, Guglielmi G, Link TM (2010) Radiation exposure in $\mathrm{X}$-ray-based imaging techniques used in osteoporosis. Eur Radiol, 20(11): 2707-2714.

10. Mettler FA, Jr., Huda W, Yoshizumi TT, Mahesh M (2008) Effective doses in radiology and diagnostic nuclear medicine: a catalog. Radiology, 248(1): 254-263.

11. Tungjai M PN, Ketnuam P, Tinlapat J, Kothan S (2018) Determination of hemolysis, osmotic fragility and fluorescence anisotropy on irradiated red blood cells as a function of kV of medical diagnostic X-rays. Int J Radiat Res. 2018, 16(1): 123-127.

12. Pornprasert S, Phusua A, Suanta $S$, Saetung $R$, Sanguansermsri T (2008) Detection of alpha-thalassemia-1 Southeast Asian type using real-time gap-PCR with SYBR Green1 and high resolution melting analysis. Eur J Haematol, 80(6): 510-514.

13. Pornprasert $S$, Wiengkum $T$, Srithep $S$, Chainoi I, Singboottra P, Wongwiwatthananukit S (2011). Detection of alpha-thalassemia-1 Southeast Asian and Thai type deletions and beta-thalassemia 3.5-kb deletion by singletube multiplex real-time PCR with SYBR Green1 and highresolution melting analysis. Korean J Lab Med, 31(3): 138142.

14. Pengkliang C, Tasanakul T, Kuropakornpong V (1994) The effectivness in screening test of carriers of thalassemia in Patthalung Hospital. Thai J Hematol Transf Med, 4(4): 123 129.
15. Winichagoon $P$, Thitivichianlert $A$, Lebnak $T$, Piankijagum A, Fucharoen S (2002) Screening for the carriers of thalassemias and abnormal hemoglobins at the community level. Southeast Asian J Trop Med Public Health, 33(Suppl 2): 145-150.

16. Pienthai N and Pornprasert S (2017) Lyophilized hemoglobin $\mathrm{E}$ control material for the dichlorophenolindophenol (DCIP) test. Clin Chem Lab Med, 55(6): e108e9.

17. Kim YK, Kwon EH, Kim DH, Won DI, Shin S, Suh JS (2008) Susceptibility of oxidative stress on red blood cells exposed to gamma rays: hemorheological evaluation. Clin Hemorheol Microcirc, 40(4): 315-324.

18. Sun L, Inaba Y, Sato K, Hirayama A, Tsuboi K, Okazaki R, et al. (2018) Dose-dependent decrease in anti-oxidant capacity of whole blood after irradiation: A novel potential marker for biodosimetry. Sci Rep, 8(1): 7425.

19. Pochano S, Noitana K, Tungjai M, Udomtanakunchai $C$ (2019) Effects of low-dose X-ray on oxidative state, lipid peroxidation, and membrane fluidity of human peripheral blood mononucleated cells. J Assoc Med Sci, 52(3): 193198.

20. Sangkitporn S, Sangnoi A, Supangwiput O, Tanphaichitr VS (2005). Validation of osmotic fragility test and dichlorophenol indophenol precipitation test for screening of thalassemia and $\mathrm{Hb}$ E. Southeast Asian J Trop Med Public Health, 36(6): 1538-1542.

21. Sanguansermsri T, Chonsuphang S, Steger HF (1998) HbE screening test. Thai J Hematol Transf Med, 8(3): 215-221.

22. Smith JT, Willey NJ, Hancock JT (2012) Low dose ionizing radiation produces too few reactive oxygen species to directly affect antioxidant concentrations in cells. Biol Lett, 8(4): 594-597. 